\title{
PERCEPÇÕES SOBRE CONSUMO E PRODUÇÃO DE ALIMENTOS: UMA ANÁLISE NA FEIRA LIVRE DE DOM PEDRITO, RS
}

Shirley Grazielli da S. Nascimento ${ }^{1}$, Daniel Hanke ${ }^{1}$, Mariana Rockenbach de Ávila², Manoel Alex Tâmara da Rosa ${ }^{1}$, Damaris Vargas ${ }^{1}$

\begin{abstract}
RESUMO - A busca por alimentos oriundos de um cultivo sem o uso, ou com o uso menos intensivo de agrotóxicos, têm levado muitos consumidores a aderirem as feiras livres mais do que aos mercados tradicionais, pois esses mesmos consumidores têm tomado cada vez mais consciência das questões relacionadas a busca por uma melhor qualidade de vida através da ingestão de uma alimentação cada vez mais saudável. O objetivo que norteou a pesquisa que deu origem a este artigo foi o de conhecer as percepções de agricultores e consumidores na feira livre municipal de Dom Pedrito sobre a produção de alimentos livres de agrotóxicos, sazonalidade na oferta de alimentos e certificação. Para tal realizou-se imersões a feira livre municipal com o intuito de entrevistar agricultores feirantes e consumidores. As entrevistas foram conduzidas com auxílio de um roteiro com questões abertas e fechadas. Os dados foram analisados através de duas técnicas distintas, quais sejam, análise de componentes principais e análise textual de discurso. Dentre os principais resultados está a importância da produção de alimentos saudáveis tanto para os agricultores quanto para os consumidores. A temática da certificação é ainda desconhecida e mal compreendida na realidade estudada justamente por não haver, por parte significativa dos consumidores, uma preocupação latente com o uso de agrotóxicos. No universo dos consumidores há um padrão distinto no que tange a preocupação com os agrotóxicos, sazonalidade e certificação, embora sejam sensíveis de formas distintas a essas temáticas. Ainda assim, é de extrema relevância debater os efeitos do uso dos agrotóxicos na produção e no consumo de alimentos para fortalecer um sistema saudável de produção no município e fomentar a pauta da certificação de produtos agroecológicos na região da campanha.
\end{abstract}

Palavras chave: alimentação saudável, certificação de alimentos, sazonalidade.

\section{PERCEPTION ABOUT CONSUMPTION AND FOOD PRODUCTION: AN ANALYSIS IN THE MARKET OF DOM PEDRITO, RS}

\begin{abstract}
The search for food without use of pesticides, has led many consumers to join street fairs more than the traditional markets. These same consumers have become increasingly aware of issues related to the search for a better life quality, through eating an increasingly healthy diet. The objective of this was to understand the farmers perceptions, as well as the consumers perception, at the Dom Pedrito municipal street fair about the production of pesticide free food, seasonality in the food supply and certification. For this, immersions were carried out at the municipal street fair in order to interview farmers and the consumers. The interviews were conducted with the help of a script with open and closed questions. The data were analyzed using two different techniques called: principal component analysis and textual discourse analysis. Among the main results is the importance of healthy food production for both farmers and consumers. The food certification is still unknown and poorly understood in the reality studied. It happens precisely because there is no latent concern with the use of pesticides by a significant part of consumers. For the consumers, it was observed that there is a distinct pattern with regard to concern with pesticides, seasonality and certification, although they are sensitive in different ways to these same themes. Even so, it is extremely important to debate the effects of pesticides on the food production and consumption. this fact is important to become strong a healthy production system in the municipality, as well as to promote the agroecological product certification in this region.
\end{abstract}

Keywords: food certification, healthy eating, seasonality.

\footnotetext{
${ }^{1}$ Universidade Federal do Pampa, campus Dom Pedrito, Rio Grande do Sul, Brasil.

${ }^{2}$ Embrapa Clima Temperado, Pelotas, Rio Grande do Sul, Brasil.
} 


\section{INTRODUÇÃO}

Produção e consumo de alimentos são temas amplamente discutidos atualmente, e têm ganhado a cena nas discussões em cenário nacional e internacional, pois os mesmos estão relacionados diretamente a qualidade de vida das populações (NASCIMENTO et al., 2019a).

Neste contexto, nos últimos anos, os consumidores se tornaram mais exigentes na hora de fazer suas compras dentro de supermercados e feiras, buscando informações através de questionamentos sobre a origem e os processos que estão sendo utilizados na produção dos alimentos, principalmente, aqueles que são de origem vegetal (ESCHER, 2019).

Além do mais, a procura por alimentos orgânicos ${ }^{3}$ tem tomado maiores dimensões, revelando não somente esse perfil do consumidor que se preocupa com a qualidade dos produtos e sua origem, mas também aponta um consumidor cada vez mais consciente no que se refere ao uso adequado do solo e demais recursos naturais e suas consequências.

Sendo assim, a busca por alimentos oriundos de um cultivo sem o uso, ou com o uso menos intensivo de agrotóxicos, têm levado muitos consumidores a aderirem as feiras livres, com o intuito de prover uma forma de alimentação cada vez mais saudável (SACCO dos ANJOS \& GODOY, 2005).

Segundo Mascarenhas e Dolzani (2008), a feira livre no Brasil constitui uma categoria de mercado varejista exercida ao ar livre, que em quase toda a sua totalidade apresenta periodicidade semanal. Desempenhando até os dias atuais papel relativamente importante no que se refere ao abastecimento urbano, embora tenha enfrentado nos últimos 30 anos políticas públicas adversas.

Existe uma enorme variedade de produtos orgânicos e agroecológicos sendo comercializados no mercado brasileiro, com grande destaque os hortifrutigranjeiros, e uma série de experiências de produção baseadas em sistemas sustentáveis. Para Altieri (2012), Agroecologia tem o propósito de permitir a implantação e desenvolvimento de estilos de agricultura com dependência mínima de agroquímicos e energia externa, permitindo assim

\footnotetext{
${ }^{3}$ O termo "alimentos orgânicos" é utilizado aqui com base no Guia alimentar para a população brasileira (2014), pois o mesmo indica que estes alimentos são oriundos de sistemas sustentáveis de produção que respeitam os recursos naturais, protegem a biodiversidade e respeitam os saberes e formas de produção tradicionais.

http://bvsms.saude.gov.br/bvs/publicacoes/guia_alimentar_populacao_brasileira_2ed.pdf
}

a regeneração da fertilidade do solo, promovendo também a manutenção da produtividade e da proteção das culturas.

Estudos demonstram (PORTILHO, CARNEIRO \& DA CUNHA GALINDO, 2010; NASCIMENTO et al., 2019b; PORTILHO, 2003) que no rol de mudanças no perfil do consumidor tem-se detectado cada vez mais "consumidores" conscientes de suas necessidades, bem como mais individualistas no que diz respeito as decisões de compras, daí surge a urgência em entendê-los (MEGIDO, 2003).

Pesquisadores e especialistas em comportamento do consumidor vem há muito tempo estudando e elaborando teorias sobre o comportamento de escolha do ser humano, e tem chegado ao entendimento de que o consumidor realiza não só a simples compra de produtos, mas, um processo que envolve uma "solução de problemas". Definido por Engel et al. (2003), esse comportamento é uma ação constante e ponderada que ocorre para trazer a satisfação de uma necessidade.

Em consonância com o movimento de consumo consciente temos o universo da produção consciente (NASCIMENTO et al., 2019b). Muito tem se discutido na atualidade sobre o papel do agricultor familiar no fomento à produção de alimentos pautados em sistemas que respeitam os tempos da natureza e não agridem a saúde de quem os produz e os consome (NASCIMENTO et al., 2019c).

Diante do exposto buscou-se compreender a percepção dos agricultores familiares feirantes e dos consumidores frequentam a feira livre Comunitária de Dom Pedrito no que se refere a produção de alimentos livres de agrotóxicos, sazonalidade na oferta de alimentos e certificação.

\section{MATERIAL E MÉTODOS}

O trabalho foi conduzido no município de Dom Pedrito, localizado na região da campanha do estado do Rio Grande do Sul (Figura 1), com aproximadamente 39000 habitantes, conforme último censo demográfico realizado (IBGE, 2010). O município encontra-se distante da capital do estado, Porto Alegre, apresentando cerca de 441,9 km de distância.

No que se refere aos tipos de produção agropecuária do município de Dom Pedrito, verificase maior destaque aos monocultivos de arroz e soja, na qual utilizam agrotóxicos para alcançarem altos índices de produtividade. Porém, o município apresenta outras 
formas de produção, policultivo ${ }^{4}$, em sua grande maioria, provenientes da agricultura familiar.

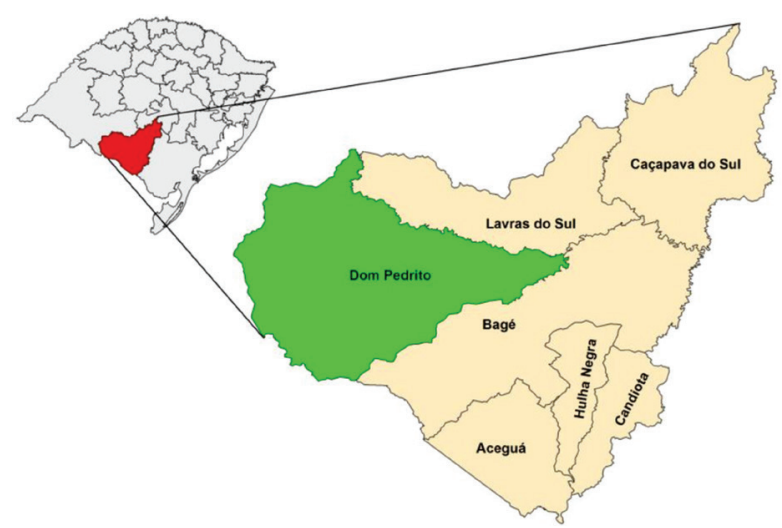

Figura 1 - Mapa do estado do Rio Grande do Sul, com destaque o município de Dom Pedrito.

Fonte: MATTE, SPANEVELLO \& ANDREATTA, 2015, p. 151.

O principal ponto destinado a comercialização dos cultivos produzidos pela agricultura familiar no município de Dom Pedrito, é a feira municipal que, embora não possua um local próprio destinado para sua realização, ocorre desde sua criação, fevereiro de 2015, semanalmente pela parte da manhã na praça central do município. Este espaço que serviu como objeto de estudo, conta com a presença de cerca de 30 produtores que comercializam seus produtos neste local, comércio este que vai além da venda de produtos cultivados no campo, pois também são comercializados desde doces, pães e artesanato em geral.

Metodologicamente este artigo ampara-se na pesquisa qualitativa de caráter exploratório (GIL, 2008) pois trabalhou-se com o levantamento de dados sobre a percepção dos agricultores familiares e consumidores da feira livre de Dom Pedrito.

As questões nortearam a pesquisa que deu origem a este artigo foram:

a) Qual o perfil dos consumidores e qual o principal motivo que os levava a frequentar a feira? b) O que pensam a respeito da produção de alimentos livres de agrotóxicos, da sazonalidade dos produtos e da certificação. c) Qual a percepção dos agricultores sobre o uso de agrotóxicos na produção de alimentos? d) O que pensam

\footnotetext{
${ }^{4}$ A produção agrícola familiar do município tem se destacado na produção de hortaliças, frutas, carnes, legumes, produtos apícolas e lãs.
}

sobre a percepção dos consumidores de seus produtos em relação a sazonalidade e a certificação.

Para realizar a interpretação dos resultados foi necessário a utilização de análise de conteúdo e análise dos componentes principais. A primeira foi fundamental para a compreensão das falas dos entrevistados e a segunda para a compreensão dos grupos distintos de consumidores que há na feira e qual suas relações com as categorias de resposta.

A análise de conteúdo, por ser uma técnica refinada, acaba por exigir do pesquisador, disciplina, dedicação, paciência e tempo. Fazendo-se necessário também, certo grau de intuição, imaginação e criatividade, sobretudo na definição das categorias de análise. Nunca esquecendo do rigor e da ética, que são fatores essenciais (BARDIN, 2010).

Por outro lado, a Análise de Componentes Principais (ACP), consiste em reescrever as coordenadas das amostras em outro sistema de eixo com maior conveniência para a análise dos dados, sendo que também pode ser usada para julgar a importância das próprias variáveis originais escolhidas, ou seja, as variáveis originais com maior peso (loadings) na combinação linear dos primeiros componentes principais são as mais importantes do ponto de vista estatístico (MOITA \& MOITA, 1998).

A técnica de amostragem utilizada foi a não probabilística por conveniência (membros da amostra que estejam mais acessíveis ao entrevistador), ou seja, agricultores e consumidores que se disponibilizaram a responder as questões propostas (BERG, 1988).

A coleta de dados foi realizada no período de janeiro a março de 2018, através de uma entrevista com 09 agricultores familiares que atuam na comercialização de seus produtos junto a feira municipal e também com 31 consumidores que compram na mesma.

\section{RESULTADOS E DISCUSSÃO}

\section{Universo dos consumidores: perfil e percepção}

No que se refere ao perfil do consumidor da feira municipal de Dom Pedrito, dos 31 consumidores entrevistados, 54,84\% são do sexo feminino e todas expuseram acreditar que os alimentos ali comercializados não apresentam agrotóxicos em suas produções. Tal resultado se assemelha ao estudo do perfil que De Carvalho Barbosa et al. (2011) realizaram, na qual revelou que a grande maioria dos frequentadores das feiras agroecológicas são do sexo feminino (58,3\%) e De Morais (2013), onde $84 \%$ foram mulheres e $16 \%$ homens. 
No entanto, tal resultado se contrapõe ao trabalho conduzido por Rocha (2010), em seu estudo sobre o perfil socioeconômico dos consumidores da feira municipal de Passo Fundo/RS, onde foi constatado que mais de 50\% dos consumidores que frequentam a feira são do sexo masculino.

Já com relação à naturalidade dos entrevistados, 23 destes $(74,19 \%)$, são naturais do município de Dom Pedrito, enquanto $25,81 \%$ são oriundos de outros municípios do estado e até mesmo de fora do RS. Cruz et al. (2008), comprovou em seu estudo sobre o perfil dos consumidores de hortaliças no município de Bom Jesus no estado do Piauí, que 53\% dos consumidores eram naturais do município.

Além disso, verifica-se no presente trabalho, a cultura dos entrevistados em adquirir alimentos oriundos de uma agricultura mais saudável (livre da presença de agrotóxicos), que vem sendo implantada dentre os moradores da cidade.

Identifica-se na Tabela 1, a faixa etária dos entrevistados, com maior representatividade na idade superior a 51 anos, o que representa um total de 48,39\% dos entrevistados. Estas informações mostram que os frequentadores da feira possuem idade mais avançada, corroborando Rucinski \& Brandenburg (2000) que estudaram uma feira agroecológica realizada na cidade de Curitiba/PR, onde a faixa etária das pessoas entrevistadas é de 41 e 51 anos, e Casemiro e Trevizan (2009), que entrevistou os baianos de Vitória da Conquista, onde a faixa etária é de 31 a 50 anos.

Tabela 1 - Faixa etária dos entrevistados neste estudo, na qual residem no município de Dom Pedrito, RS, Brasil.

\begin{tabular}{ccc}
\hline $\begin{array}{c}\text { Faixa etária } \\
\text { (idade) dos } \\
\text { entrevistados }\end{array}$ & $\begin{array}{c}\text { Número total de } \\
\text { entrevistados }\end{array}$ & Percentual \\
\hline 20 aos 30 anos & 4 & $12,90 \%$ \\
31 aos 40 anos & 8 & $25,81 \%$ \\
41 aos 50 anos & 4 & $12,90 \%$ \\
51 aos 60 anos & 7 & $22,58 \%$ \\
Acima dos 61 anos & 8 & $25,81 \%$ \\
Total & 31 & $100 \%$ \\
\hline
\end{tabular}

Fonte: Pesquisa de campo, 2018.
Em relação à profissão dos consumidores verificou-se que há uma diversidade de ocupação entre os entrevistados. Destaca-se entre estes os são funcionários públicos, 22,58\% $(n=7)$ e os aposentados 19,35\% $(n=6)$, como pode ser observado na Tabela 2.

Tabela 2 - Profissão dos consumidores entrevistados neste estudo, na qual residem no município de Dom Pedrito, RS, Brasil.

\begin{tabular}{lcc}
\hline $\begin{array}{l}\text { Profissão dos } \\
\text { entrevistados }\end{array}$ & $\begin{array}{c}\text { Número } \\
\text { total de } \\
\text { entrevistados }\end{array}$ & Percentual \\
\hline $\begin{array}{l}\text { Funcionário público } \\
\text { Aposentado }\end{array}$ & 7 & $22,58 \%$ \\
Comerciante & 3 & $19,35 \%$ \\
$\begin{array}{l}\text { Doméstica/dona de casa } \\
\begin{array}{l}\text { Outras profissões } \\
\text { (atendente no comércio, }\end{array}\end{array}$ & 2 & $9,68 \%$ \\
$\begin{array}{l}\text { diaristas, engenheiro, } \\
\text { veterinário) }\end{array}$ & 13 & $6,45 \%$ \\
Total & 31 & $109 \%$ \\
\hline
\end{tabular}

Fonte: Pesquisa de campo, 2018.

Quanto ao nível de escolaridade dos consumidores, se constatou que a grande maioria dos entrevistados possui ensino médio completo (45,16\%), seguidos de $25,81 \%$ com ensino superior completo. Comparando com os resultados de outros trabalhos que procuravam traçar o perfil dos consumidores em outras localidades do país, como por exemplo, De Carvalho Barbosa et al. (2011), onde observa-se que $29,8 \%$ dos entrevistados afirmam ter concluído o ensino médio e $36,9 \%$ dizem possuir curso superior completo. Segundo Kotler (2000), fatores pessoais que se referem à idade, estilo de vida, nível de instrução, ocupação e circunstâncias econômicas também são fatores que determinam o comportamento de consumo.

Em relação ao principal motivo que levava os consumidores entrevistados a frequentarem a feira, 11 entrevistados $(35,48 \%)$ disseram que a possibilidade de aquisição de alimentos agroecológicos era o principal motivo que os impulsionava a frequentarem o local, sendo seguidos pela localização $(29,03 \%)$ e preço dos produtos $(22,58 \%)$, respectivamente. Esses dados encontram par em outras pesquisas realizadas sobre consumidores em feiras e 
demonstram a importância da consolidação destes espaços para o impulsionamento de uma alimentação saudável (GODOY \& DOS ANJOS, 2007; WUERGES \& SIMON, 2007).

\section{Percepções dos consumidores}

Dando sequência as discussões sobre os resultados da pesquisa na seção que segue, será apresentado o universo de percepções dos consumidores em relação ao uso de agrotóxicos na produção de alimentos, sazonalidade dos produtos vendidos na feira e a importância da certificação.

Para melhorar a compreensão das discussões apresenta-se a categorização das questões que nortearam as análises expressas pelo componente principal. A tabela 3 traz uma síntese das questões norteadoras e os agrupamentos realizados.

Tabela 3 - Abreviação dentro do agrupamento das questões abordadas no presente estudo.

\begin{tabular}{clcc}
\hline Questões & Descrição das questões & Abreviações \\
\hline 3 & $\begin{array}{l}\text { Percepção sobre o uso de } \\
\text { agrotóxicos na produção dos } \\
\text { alimentos }\end{array}$ & PUAA \\
4 & $\begin{array}{l}\text { Preocupação com os problemas } \\
\text { relacionados com o uso de } \\
\text { agrotóxicos }\end{array}$ & PPRA \\
5 & $\begin{array}{l}\text { Preocupação com a } \\
\text { sazonalidade dos produtos }\end{array}$ & Sazonalidade \\
6 & $\begin{array}{l}\text { Percepção sobre a importância } \\
\text { da certificação }\end{array}$ & Certificação \\
\hline
\end{tabular}

Fonte: Pesquisa de campo, 2018.

A ACP foi capaz de explicar $75,5 \%$ da variância total dos dados. Sendo que os eixos que representam os componentes principais (CP) apresentam uma estrutura dos dados estável e de fácil interpretação, dividindo-se em dois eixos: O CP 1 (eixo x) que explicou 47,9\% da variância total, e o CP2 (eixo y) responsável por 29,6\%.

Foram utilizadas quatro variáveis no questionário (PUAA, PPRA, sazonalidade e certificação) que ajudaram nitidamente na definição das diferenças das amostras (consumidores), apresentando o seguinte ajuste: a) As variáveis PPRA e PUAA foram mais expressivas para definir o primeiro componente principal (CP 1 - eixo x), e aparecem no sentido positivo do eixo (a direita em relação ao eixo x); b) A variável sazonalidade definiu fortemente o eixo 2, enquanto a variável certificação apresentou um peso menor estando basicamente relacionada tanto com o eixo 1 (x) quanto com o eixo 2 (y),

Em síntese, o eixo 1 representa a preocupação dos consumidores quanto ao uso de agrotóxicos na produção e aos problemas de saúde que derivam disso. Enquanto que o eixo 2 representa a importância da sazonalidade para o consumidor, além de aspectos também relacionados com a percepção sobre a certificação, conforme a Tabela 4 .

Tabela 4 - Valores de "loadings" da relação entre as variáveis originais e os componentes principais.

\begin{tabular}{lcc}
\hline \multicolumn{1}{c}{ Variável/eixo } & Eixo 1 (CP 1) & Eixo 2 (CP 2) \\
\hline PUAA & 0,63 & $-0,26$ \\
PPRA & 0,63 & 0,06 \\
Sazonalidade & $-0,10$ & 0,83 \\
Certificação & 0,44 & 0,48 \\
\hline
\end{tabular}

Fonte: Pesquisa de campo, 2018.

Dessa forma, os consumidores que aparecem à direita e acima no gráfico são mais preocupados com o uso de agrotóxicos e com os problemas relacionados à saúde causados por eles, acreditam mais na importância da certificação e relevam mais o aspecto da sazonalidade. Assim sendo, os consumidores que aparecem à esquerda e abaixo no gráfico apresentado na Figura 2, são menos preocupados com o uso de agrotóxicos, pouco acreditam na certificação e pouco se importam com o aspecto da sazonalidade.

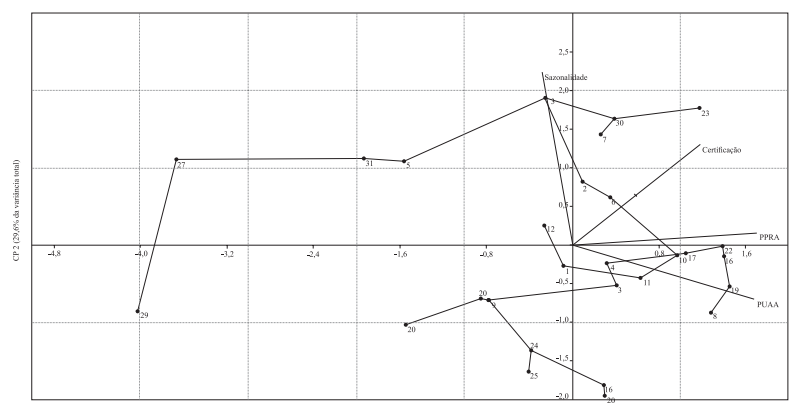

Figura 2 - Diagrama de ordenação por componentes principais (ACP).

Fonte: Pesquisa de campo, 2018.

Já, os demais consumidores ("à direita e abaixo" e "à esquerda e em cima") formam gradientes de transição entre os dois extremos comentados anteriormente. 
Consumidores e preocupação com agrotóxicos: problemas relacionados à saúde humana

Como dito anteriormente, o eixo 1 explica a maior parte da variância dos dados $(47,9 \%)$ e é definido principalmente por PUAA e PPRA, e desta forma pode-se afirmar que, para o público em geral, a preocupação com o uso de agrotóxicos é importante para definir o perfil de consumidores da feira, porém é importante salientar que isso não quer dizer que todos têm essa preocupação, eles podem se preocupar ou não com os agrotóxicos.

Como pode-se verificar por parte de alguns entrevistados, a questão da produção com agrotóxico não é o fator que mais os leva a comprar na feira, como pode ser observado em alguns trechos das entrevistas realizadas abaixo:

"[...] pelo fato de nem todos os produtores possuem condições financeiras para investir [em produções sem o uso de agrotóxicos]..." (Entrevista 1, Feira Livre 2018)

Mesmo PUAA e PPRA sendo as variáveis de maior importância na definição do universo amostral (consumidores), não há uma boa correlação entre essas duas variáveis, como pode ser verificado pela regressão linear abaixo (Figura 3).

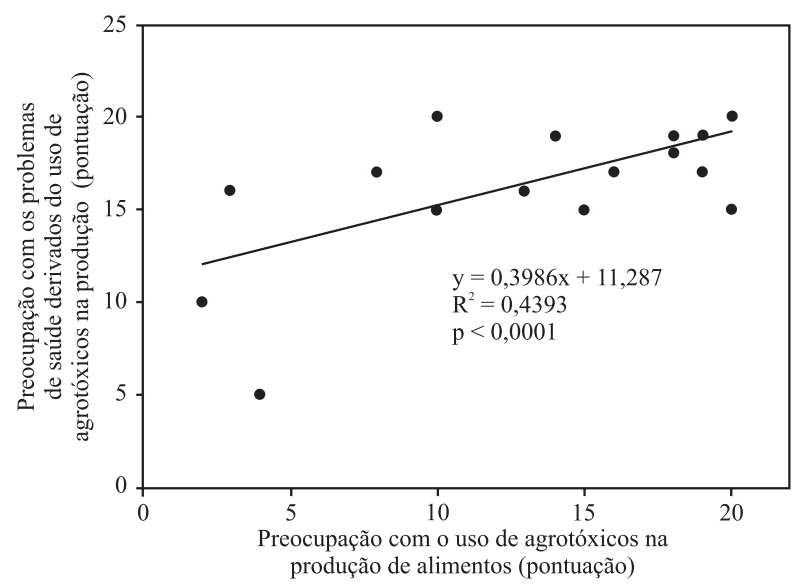

Figura 3 - Regressão linear entre as variáveis PUAA e PPRA. Fonte: Pesquisa de campo, 2018.

Observando o coeficiente de determinação da regressão linear $\left(R^{2}=0,4393\right)$, verifica-se que, na percepção dos consumidores da feira, apenas aproximadamente $44 \%$ da preocupação com o uso de agrotóxicos está relacionada com a preocupação com os problemas de saúde derivados do uso dessas substâncias na produção.
Embora De Carvalho Barbosa et al. (2011), tenham constatado em sua pesquisa que cerca de $61 \%$ das pessoas entrevistadas consomem orgânicos, por estes serem mais saudáveis conduz a uma percepção de que há, para o consumidor, uma forte conexão entre alimentos orgânicos e saúde. E então, é muito provável que haja falta clareza, por parte da população de Dom Pedrito sobre os impactos negativos que os agrotóxicos possuem sobre a saúde dos produtores e dos consumidores.

Dos 31 consumidores, 11 apresentam menor preocupação com o uso de agrotóxicos na produção, uma vez que isso representa $35,4 \%$ dos consumidores. Esses consumidores aparecem ao lado esquerdo (em relação ao eixo x) no diagrama de ordenação. Dentre esses, existem 5 consumidores que se destacam com relação à essa despreocupação $(5,26,27,29$ e 31 - especialmente os consumidores 27 e 29, segundo pode ser observado através da Figura 4, encontram-se mais afastados no ponto central do gráfico), ou seja, 16,1\% dos consumidores da feira.

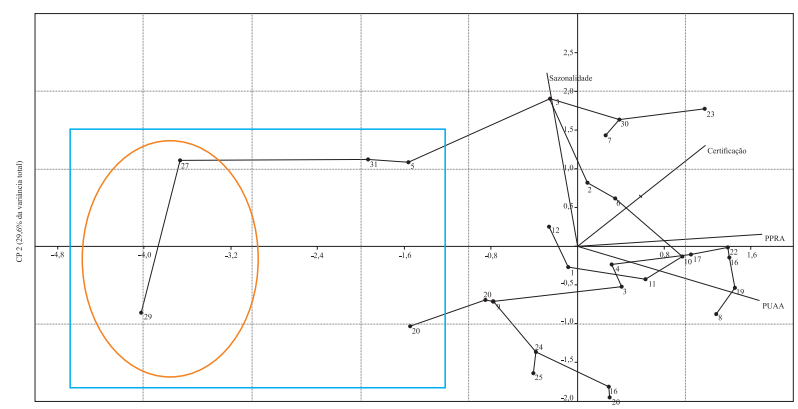

Figura 4 - Identificação dos casos isolados no diagrama de dispersão.

Fonte: Pesquisa de campo, 2018.

Os entrevistados relataram que acreditam que não há agrotóxico pela aparência do produto, o que pode representar uma falha de percepção em relação a qualidade do produto, pois os alimentos produzidos com agrotóxico geralmente possuem boa aparência.

Os outros 20 consumidores apresentaram maior preocupação com relação ao uso de agrotóxicos na produção, e da mesma forma se preocuparam mais com os desdobramentos do uso dessas substâncias na saúde. Entre esses se destaca um grupo que apresenta maior preocupação com relação a esse aspecto, na qual representa $31 \%$ dos consumidores e, aproximadamente $70 \%$ apresentam idade igual ou superior a 60 anos (Figura 4). 
Em relação a utilização de agrotóxicos pode -se observar que uma parcela significativa dos entrevistados preocupam-se com o uso deste produto e os impactos que isto causa tanto para quem produz os alimentos quanto para quem os consome, pois a manipulação e consumo deste produto está associado a maior incidência de câncer, assim como também, outras doenças em geral (RODRIGUES, et al, 2018; SILVA, et al, 2005).

Porém, ainda existe um número significativo de pessoas (consumidores) que ainda não entendem ou até mesmo desconhecem os reais problemas que a utilização exagerada de agrotóxicos, por parte dos produtores, pode gerar. Não somente com relação a vida dos mesmos, mas também com o próprio meio ambiente que recebe uma alta carga (dose) de agrotóxicos.

Segundo Jardim (2009) as famílias não ignoram o risco dos agrotóxicos. Os dados evidenciaram que as pessoas já ouviram falar nos perigos do consumo excessivo dos agrotóxicos, mas não inserem tais riscos em seus repertórios de preocupações de natureza privada e pública associadas à alimentação. Ainda para o mesmo autor, a falta de interesse das pessoas pelo assunto é bastante clara.

\section{Os consumidores e a preocupação com a sazonalidade e certificação de alimentos}

Mesmo a feira livre de Dom Pedrito não sendo uma feira certificada agroecologicamente, pode-se perceber entre os consumidores que há uma confiança nos agricultores familiares feirantes. Segundo Cuenca et al. (2007), em seu trabalho intitulado "Perfil do Consumidor e do Consumo de Produtos Orgânicos no Rio Grande do Norte", na qual aborda o reconhecimento dos produtos orgânicos no mercado, constatou-se que o selo de certificação do produto induz $81,4 \%$ dos entrevistados ao consumo. Assim como Rucinski e Brandenburg (2000) que descreveram que o perfil dos consumidores de Curitiba indicara existir uma relação de confiança com o produtor e com o produto orgânico, pois compram seus alimentos de forma independente da presença do selo do Instituto Biodinâmico - IBD que atesta a procedência dos alimentos.

Pode-se verificar por parte de alguns entrevistados, no caso um grupo contando com um total de 7 consumidores, a questão da certificação não é o fator que mais os leva a comprar na feira, pois nestes casos, o critério de compra é a confiança que o consumidor deposita no agricultor, conforme pode ser observado em alguns trechos das entrevistas realizadas abaixo:
"[...] por conhecer os agricultores que trabalham ali [na feira]..." (Entrevista 16, Feira Livre 2018).

“[...] pela confiança que eu possuo nos produtos que compro..." (Entrevista 19, Feira Livre 2018).

Alguns consumidores apresentaram justificativas muito interessantes sobre a durabilidade dos produtos, que foi o caso de 2 dos entrevistados, que comentaram que pelo fato dos produtos comercializados na feira não possuírem agrotóxicos tem um tempo de duração inferior aos que possuem agrotóxicos. Outro relato interessante foi o que uma consumidora descreveu, pois, a mesma disse que possui uma expertise em verificar se tem agrotóxico ou não um alimento, já que trabalha com alimentos e conhece a qualidade e procedência de um produto.

Aproximadamente 20 consumidores (64,5\%) acreditam que a sazonalidade dos produtos da feira não é um problema para o planejamento do consumo familiar (cardápios e etc.) durante o ano.

Segundo os próprios entrevistados, se não há um alimento na feira, este que está em falta é automaticamente substituído por outro que apresente características semelhantes.

Há alguns consumidores mais sensíveis em relação à sazonalidade dos produtos, onde 5 atribuíram maior importância para a sazonalidade, bem como para o mecanismo de certificação dos alimentos.

Pode ser percebido que muitos dos consumidores entrevistados não sabem o que significa o termo sazonalidade, e desta forma foi possível realizar uma comparação com o trabalho publicado por Barros et al. (2008), que considerou que os dados obtidos em sua pesquisa sobre o entendimento dos consumidores a respeito do consumo de banana, revelaram ainda que o consumidor não tem conhecimento sobre o que é a sazonalidade da produção.

Dentre estes consumidores, pode-se observar que o nível de sensibilidade com relação a certificação de alimentos comercializados na feira, pois todos descreveram que se houvesse certificação, os produtos trariam uma maior credibilidade na hora de realizarem suas compras, como pode ser observado em pequenos trechos de suas algumas entrevistas:

"[...] Sim. Com certeza me sentiria mais tranquila em consumir um produto que apresenta um selo que comprova sua qualidade..." (Entrevista 7 , Feira Livre 2018). 
“[...] sim, pois já gosto de adquirir produtos de qualidade e através deste selo de certificação, compraria de olhos fechados o que é vendido aqui neste espaço público..." (Entrevista 23, Feira Livre 2018).

Também, foi percebida uma relação muito forte entre consumidores e produtores e nesse sentido, destaca-se o fato de os consumidores acreditarem que determinado produto é orgânico (não apresenta agrotóxicos em sua produção) com base na relação que eles têm com o produtor, bem como por sua suposta na sua percepção das características dos produtos orgânicos.

Para Barbosa e Lages (2006), em seu trabalho foi constatado que a localidade onde foi realizada a pesquisa de campo (feira) apresenta um perfil peculiar para os consumidores, tornando a certificação orgânica um aspecto secundário e até desconhecido pela maioria. Fato este, também observado na feira municipal de Dom Pedrito.

\section{O universo de significados apresentados pelos agricultores familiares}

Nesta seção será apresentado os resultados levantados junto aos agricultores familiares feirantes. Para o melhor entendimento das discussões apresenta-se a categorização das questões que nortearam as análises contempladas pela ACP. A tabela que segue contempla as siglas utilizadas ao longo das discussões:

Tabela 5 - Abreviação dentro do agrupamento das questões abordadas no presente estudo.

\begin{tabular}{clll}
\hline Questões & Descrição das questões & Abreviações \\
\hline 4 & $\begin{array}{l}\text { Importância do uso de } \\
\text { recursos externos }\end{array}$ & IRE \\
5 & $\begin{array}{l}\text { Preocupação sobre alimentos } \\
\text { produzidos com agrotóxicos }\end{array}$ & PAPA \\
6 & $\begin{array}{l}\text { Percepção dos agricultores } \\
\text { sobre a importância que os } \\
\text { consumidores dão para os }\end{array}$ & A \\
& $\begin{array}{l}\text { alimentos produzidos com } \\
\text { agrotóxicos }\end{array}$ & \\
7 & Importância da certificação & IC \\
8 & $\begin{array}{l}\text { Agregação de valor pelo não } \\
\text { uso de agrotóxicos }\end{array}$ & (AVA) \\
\hline
\end{tabular}

Com relação aos dados levantados junto aos agricultores familiares feirantes a análise de componentes principais (ACP) explicou 70,8 \% da variância total dos dados. O CP 1 (eixo x) explicou 43,5 \% da variância total, ao passo que o $\mathrm{CP} 2$ apresentou $27,3 \%$, como representado nas Figuras 5 e 6.

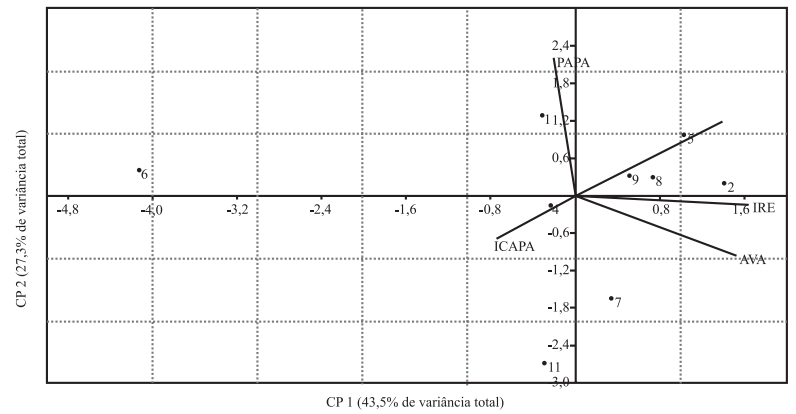

Figura 5 - Diagrama de ordenação por componentes principais (ACP) - sem ligação das amostras (agricultores) pela árvore geradora.

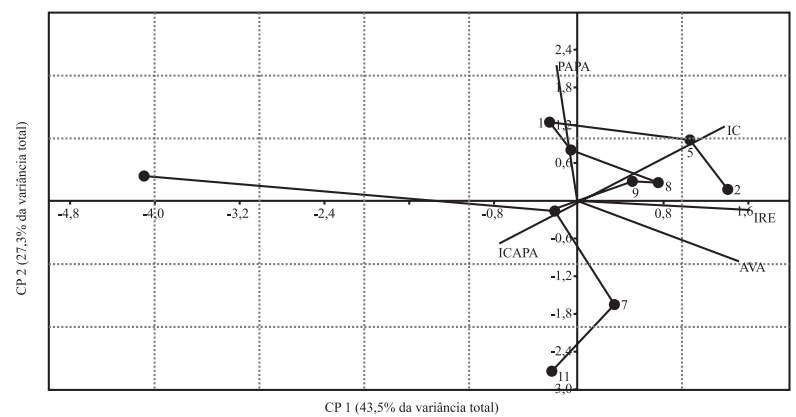

Figura 6 - Diagrama de ordenação por componentes principais (ACP) - com uso da técnica do algoritmo da árvore geradora por medidas de similaridade para estudo da estrutura de agrupamento das amostras.

Todas variáveis utilizadas no questionário (IRE, PAPA, ICAPA, IC e AVA) ajudaram nitidamente a definir as diferenças das amostras (agricultores) e apresentaram que as variáveis PAPA e ICAPA foram mais expressivas para definir o segundo componente principal (CP 2 - eixo y do gráfico), na qual foram inversamente correlacionadas entre si.

As variáveis IRE, AVA e IC foram mais expressivas para definir o primeiro componente principal (CP 1 - eixo x do gráfico). Sendo assim, as cinco variáveis iniciais se transformaram em apenas duas, independentes entre si, que são o eixo X (CP 1) e eixo Y (CP 2) (Tabela 5). 
Tabela 5 - Valores de "loadings" da relação entre as variáveis originais e os componentes principais

\begin{tabular}{ccc}
\hline Variável/eixos & CP 1 (eixo x) & CP 2 (eixo y) \\
\hline IRE & 0.5617 & 0.1588 \\
PAPA & -0.1495 & 0.7857 \\
ICAPA & -0.2041 & -0.5645 \\
IC & 0.5822 & 0.02831 \\
AVA & 0.5305 & -0.195 \\
\hline
\end{tabular}

A partir disso, podemos interpretar a posição em que os agricultores estão no gráfico (diagrama de ordenação).

O CP 1 é definido pela importância da certificação (IC), agregação de valor pelo não uso de agrotóxicos (AVA) e pela importância atribuída utilização de recursos externos na produção (IRE). Ou seja, o CP 1 (eixo $\mathrm{x}$ ) define uma variável de caráter econômico. Isso significa que tudo que está à direita em relação ao eixo $\mathrm{X}$ são amostras (agricultores) que dão maior importância para as questões de ordem econômica, inclusa a questão da certificação.

O CP 2 é definido pela preocupação dos agricultores sobre a produção de alimentos produzidos com agrotóxicos (PAPA) e pela percepção dos agricultores sobre a importância atribuída pelos consumidores para os alimentos produzidos com agrotóxicos (ICAPA) - ou seja, uma variável (eixo y) relacionada à "preocupação com a produção e percepção do consumo". Isso significa que tudo que está acima em relação ao eixo Y são amostras (agricultores) que apresentam maior preocupação com o uso de agrotóxicos, assim como acreditam que os consumidores atribuem menor importância ao uso de agrotóxicos.

Os agricultores 1, 2, 3, 5, 8, 9 e 10 formam um grupo parcialmente heterogêneo, e apresentam maior preocupação com as questões econômicas e certificação (com exceção dos agricultores 1 e 10 que são menos sensíveis a esses aspectos de ordem econômica). Nesse grupo os agricultores apresentam maior preocupação com o uso de agrotóxicos na produção de alimentos, mas, os agricultores 1, 2 e 5 atribuem uma menor importância pelos consumidores ao uso desses produtos na definição da compra. Verifica-se que três agricultores desse subgrupo atribuem o máximo de importância para a certificação.

O agricultor 6 forma um grupo isolado de caráter intermediário - menor preocupação com aspectos econômicos, mas bastante preocupado com o uso de agrotóxicos na produção e que acredita que, de fato, os consumidores se preocupam com os agrotóxicos na produção. $\mathrm{O}$ agricultor 6 se destaca expressivamente de todos os demais - formando também um grupo isolado. Esse é o menos sensível as questões econômicas e certificação e atribuí o máximo de preocupação para o uso de agrotóxicos na produção e que acredita que o consumidor se preocupa com o uso desses produtos na produção de alimentos.

Os agricultores 7 e 11 formam também um grupo isolado - atribuí menor importância ao uso de recursos externos e com menor preocupação com o uso de agrotóxicos na produção. Entretanto, acreditase que a certificação seja importante e que há agregação de valor pelo não uso de agrotóxicos. Confirmando esse comportamento, esse agricultor também acredita que o consumidor se importa expressivamente com a aplicação desses produtos na produção.

\section{CONCLUSÕES}

Os consumidores da feira de Dom Pedrito representam um grupo bastante heterogêneo, tanto em relação à idade, formação e, origem socioeconômica e cultural. Algo que foi muito notório, é a grande proporção de consumidores com idade acima de 50 anos.

Verificou-se que a temática da certificação é bastante desconhecida e mal compreendida na realidade atual, justamente por não haver, por parte significativa dos consumidores, uma preocupação latente com o uso de agrotóxicos.

No que se refere a sazonalidade, pode-se observar que, não representa empecilho para os consumidores, pois se não há um produto que seja utilizado pelos consumidores, estes acabam por substituir por outros que apresentem características semelhantes aos que estão ausentes na feira.

Em relação aos agricultores da feira, os mesmos são diferentes em termos de: i) percepção com relação ao consumidor e; ii) racionalidade econômica. Além disso, eles apresentam distintos níveis de preocupação com o uso de agrotóxicos na produção de alimentos.

Por fim, ressalta-se que, debater os efeitos do uso dos agrotóxicos na produção e no consumo ajuda a fortalecer a pauta da certificação de produtos de base ecológica. 


\section{LITERATURA CITADA}

ALTIERI, M. Agroecologia, agricultura camponesa e soberania alimentar. Revista Nera, n. 16, p. 22-32, 2012.

BARBOSA, L. C. G.; LAGES, A. M. G. Crença e certificação de produtos orgânicos: o exemplo da feira livre de Maceió. Anais... III Encontro da ANPPAS, 2006.

BARBOSA, S. D. C.; MATTEUCCI, M. B. D. A.; LEANDRO, W. M.; LEITE, A. F.; CAVALCANTE, É. L. S.; ALMEIDA, G. Q. E. D. Perfil do consumidor e oscilações de preços de produtos agroecológicos. Pesquisa Agropecuária Tropical, v. 41, n. 4, p. 602-609, 2011.

BARDIN, L. Análise de conteúdo. 4. ed. Lisboa: Edições 70, 2010.

BARROS, M. A. B.; LOPES, G. M. B.; WANDERLEY, M. B. Tipologia do consumo de frutas: um estudo sobre o comportamento do consumidor de banana. Revista Produção Online, v. 7, n. 4, 2008.

BERG, S. Snowball sampling - I. Encyclopedia of statistical sciences, 2004.

CASEMIRO, A. D.; TREVIZAN, S. D. P. Alimentos orgânicos: desafios para o domínio público de um conceito. In: International workshop advances in cleaner production. key elements for a sustainable world: energy, water and climate change, 2009.

CRUZ, P. P.; MOREIRA, G. R.; FERREIRA, F. S.; MORAES, F. B.; SOUSA, F. J. L.; MOURA, F. J. G.; COELHO, R. F.; LIMA, M. P. D.; CARVALHO, R. M.; ALMEIDA, A. A. Perfil dos consumidores de hortaliças da feira livre de Bom Jesus, Piauí. Horticultura Brasileira, v. 26, n. 2, 2008.

CUENCA, M. A. G. Perfil do consumidor e do consumo de produtos orgânicos no Rio Grande do Norte. Embrapa Tabuleiros Costeiros, 2007.

IBGE. Censo Demográfico. Disponível em: http://www. ibge. gov. br. Acesso em 2017.

DE MORAIS, F. F. Perfil dos consumidores de produtos orgânicos da feira agroecológica do mercado municipal de Goiânia-GO. Revista Verde de Agroecologia e Desenvolvimento Sustentável, v. 7, n. 4, p. 64-70, 2013.

ENGEL, J. F.; BLACKWELL, R. D.; MINARD, P. W. Comportamento do Consumidor.

Rio de Janeiro: LTC, 2003.

ESCHER, Fabiano. As Novas Ordens Alimentares. Estudos Sociedade e Agricultura, p. 215-224, 2019.
GIL, A. C. Métodos e técnicas de pesquisa social. 6. ed. São Paulo: Atlas, 2008.

GODOY, W. I.; DOS ANJOS, F. S. A importância das feiras livres ecológicas: um espaço de trocas e saberes da economia local. Cadernos de Agroecologia, v. 2, n. 1, 2007.

JARDIM, I. C. Sales Fontes. Resíduos de agrotóxicos em alimentos: uma preocupação ambiental global - Um enfoque às maçãs. Química Nova, 2009.

KOTLER, P. Administração de marketing: a edição do novo milênio. 8. ed. São Paulo: Prentice Hall, 2000.

MASCARENHAS, G.; DOLZANI, M. C. S. Feira livre: territorialidade popular e cultura na metrópole contemporânea. Ateliê Geográfico, v. 2, n.4, p. 72-87, 2008.

MATTE, A.; SPANEVELLO, R. M.; ANDREATTA, T. Perspectivas de sucessão em propriedades de pecuária familiar no município de Dom Pedrito-RS. Holos, v. 1, p. 144-159, 2015.

MEGIDO, A. J.; XAVIER, L. T. Marketing \& Agrobusiness. São Paulo: Atlas, 2003.

MOITA NETO, J. M.; MOITA, G. C. Uma introdução à análise exploratória de dados multivariados. Química Nova, v. 21, p. 467-469, 1998. Rocha (2010),

NASCIMENTO, S. G.; BECKER, C.; DA SILVA, F. N.; CALDAS, N. V.; DE ÁVILA, M. R. Produção agroecológica e Segurança Alimentar e Nutricional (Brasil). Revista de Ciências Agrárias, v. 42, n. 1, p. 294-304, 2019a.

NASCIMENTO, S. G. S.; VERDUM, A. H.; HANKE, D.; AVILA, M. R.; BECKER, C. Consumo verde: uma análise sobre o comportamento ambiental dos consumidores de Dom Pedrito (Rio Grande do Sul - Brasil). Revista Brasileira de Meio Ambiente. https://doi.org/10.5281/ zenodo.3566146, v. 7, p. 116-130-130, 2019b.

NASCIMENTO, S. G. S.; MANCILHA, V. E.; HANKE, D.; BECKER, C.; AVILA, M. R. Diversificação produtiva como estratégia de apoio à segurança alimentar e nutricional entre os agricultores familiares na Campanha Gaúcha. Revista de Ciências Agronômicas, v. 28, p. 82-97, 2019.

PORTILHO, F.; CARNEIRO, C. B. M.; DA CUNHA GALINDO, F. L. O. Consumo e meio ambiente: como a educação ambiental brasileira aborda esta relação. Paper apresentado no $V$ Encontro Nacional da ANPPAS. Florianópolis, 2010.

PORTILHO, F. Consumo verde, consumo sustentável e a ambientalização dos consumidores. Unicamp/IFCH, 2003.

ROCHA, H. C.; COSTA, C.; CASTOLDI, F. L.; CECCHETTI, D.; OLIVEIRA CALVETE, E. D.; 
SANTOS LODI, B. D. Perfil socioeconômico dos feirantes e consumidores da feira do produtor de Passo Fundo, RS. Ciência Rural, v. 40, n. 12, 2010.

RODRIGUES, S. F. M. et al. Trabalhador do campo e as doenças causadas pelo uso de agrotóxicos. Cadernos de Agroecologia, v. 13, n. 1, 2018.

RUCINSKI, J.; BRANDENBURG, A. Consumidores de alimentos orgânicos em Curitiba. Monografia de graduação, UFPR/Deciso, Curitiba, 2000.

SACCO DOS ANJOS, F.; GODOY, W. I.; CALDAS, N. V. As feiras-livres de Pelotas sob o império da globalização: perspectivas e tendências. 1. ed. Pelotas: Editora e Gráfica Universitária, 2005. v. 1. 197p.

SILVA, J. M. et al. Agrotóxico e trabalho: uma combinação perigosa para a saúde do trabalhador rural. Ciência \& saúde coletiva, v. 10, n. 4, p. 891-903, 2005.

WUERGES, E. W.; SIMON, Á. A. Feiras-Livres como uma forma de popularizar a produção e o consumo de hortifrutigranjeiros produzidos com base na agroecologia. Revista Brasileira de Agroecologia, v. 2, n. 2, 2007.

Recebido para publicação em 15/03/2019, aprovado em 22/01/2020 e publicado 30/07/2020. 